\title{
LINEAR CALIBRATION IN ION CHROMATOGRAPHY BY CALCULATING TOTAL AMOUNTS OF SAMPLE FROM MEASURED CONDUCTIVITY DATA
}

\author{
M. J. VAN OS* and J. SLANINA \\ Netherlands Energy Research Foundation (ECN), Petten, N.H. (The Netherlands) \\ C. L. DE LIGNY and J. AGTERDENBOS \\ Laboratory for Analy tical Chemistry, State University, Croesestraat 77A, Utrecht \\ (The Netherlands)
}

(Received 9th May 1983)

\section{SUMMARY}

Calibration graphs in ion chromatography are generally not linear, if a suppressor column and a conductivity detector are employed. The main reason for this is that the dissociation equilibrium of the eluent (which is a weak acid after eluent suppression) is shifted by $\mathrm{H}^{+}$ions from the sample, which are formed in the suppressor column. Therefore a formula is derived in which the suppression of the eluent dissociation by the sample is considered. Application of this formula for chloride, nitrate and sulphate samples in succinate and carbonate eluents results in linear calibration graphs in the range $0-40 \mathrm{mg} \mathrm{l}^{-1}$ when peak areas are used.

Ion chromatography, introduced by Small et al. in 1975 [1], is a useful and sensitive method for the determination of inorganic anions, and has found widespread application, especially in environmental analyses [2]. When a conductometric cell is used as a universal detector, the use of a suppressor column improves sensitivity and detection limit. Unfortunately, in the eluate from the suppressor column, the eluent is a weak acid and the sample is a strong acid, the $\mathrm{H}^{+}$ions of which suppress the ionization of the weak acid. Consequently, the contribution of the eluent to conductivity is not constant, but decreases with increasing sample concentration. As a result, calibration graphs, whether based on peak heights or peak areas, cannot be expected to be linear. This was observed in earlier work [3].

In this report a formula is derived, by which the sample concentration can be calculated from the measured conductivity. The displacement of eluent ions from the separator column by sample ions and the eluent dissociation after suppression are considered in the calculation of linear calibration graphs. 
In ion chromatography with eluent suppression and conductivity detection, the following processes take place. A mixture of anions $\mathrm{X}^{-}, \mathrm{Y}^{-}$and $\mathrm{Z}^{-}$is injected into an eluent stream which flows through an anion-exchange column, where the separation occurs. If the sample anions are eluted with a salt of a dibasic acid, $\mathrm{H}_{2} \mathrm{~B}$, then in the eluate from the separator column $\mathrm{X}^{-}, \mathrm{Y}^{-}$and $\mathrm{Z}^{-}$are present as the sodium salts $\mathrm{NaX}, \mathrm{NaY}$ and $\mathrm{NaZ}$, together with an excess of $\mathrm{Na}_{2} \mathrm{~B}, \mathrm{NaHB}$ (and a small amount of $\mathrm{H}_{2} \mathrm{~B}$ ). To reduce the eluent contribution to the conductivity, a second column (suppressor column) is inserted between separator column and detector. This is a cationexchange column in the $\mathrm{H}^{+}$-form, where all cations are exchanged for $\mathrm{H}^{+}$. In the eluate from the suppressor column, the sample ions are present as strong acids ( $\mathrm{HX}, \mathrm{HY}$ and $\mathrm{HZ}$ ) and the eluent as a weak acid $\mathrm{H}_{2} \mathrm{~B}$. Since the equivalent conductance of $\mathrm{H}^{+}$is $7 \times$ higher than that of $\mathrm{Na}^{+}$, the contribution of the sample ions $\left(\mathrm{X}^{-}\right.$together with $\left.\mathrm{H}^{+}\right)$to the conductivity signal is increased, but the contribution of the eluent (determined by the degree of ionization of the weak acid $\mathrm{H}_{2} \mathrm{~B}$ ) is reduced. Thus, eluent suppression improves the sensitivity and reduces the background conductivity. Consequently, the detection limit also is improved.

It has been shown [4] that the elution of the sample ions is governed by the concentration of divalent $\mathrm{B}^{2-}$ ions in the eluate. Thus the ion-exchange column can be considered as in dynamic equilibrium with the divalent eluent ions $B^{2-}$. After sample injection on the top of the column (Fig. 1a), a dynamic equilibrium is set up in which the sample ions partition between the mobile phase and the stationary phase, an equivalent number of eluent ions $\mathrm{B}^{2-}$ being displaced from the stationary phase. Thus the eluent concentration in the stationary phase is locally reduced and the eluent concentration in the mobile phase is locally increased (Fig. 1b). When $\Delta C_{\mathrm{B}^{2-}, \mathrm{s}}$ is the decrease of eluent concentration and $C_{\mathrm{X}^{-}, \mathrm{s}}$ is the sample concentration in the stationary phase, then

$\Delta C_{\mathrm{B}^{2-}, \mathrm{s}}=1 / 2 C_{\mathrm{X}^{-}, \mathrm{s}}$

The local deficit of eluent ions in the stationary phase equals the local excess of eluent $\Delta C_{\mathrm{B}, \mathrm{m}}$ (where $\Delta C_{\mathrm{B}, \mathrm{m}}=\Delta C_{\mathrm{B}^{2-}, \mathrm{m}}+\Delta C_{\mathrm{HB}^{-}, \mathrm{m}}+\Delta C_{\mathrm{H}_{3} \mathrm{~B}, \mathrm{~m}}$ ) in the mobile phase, hence

$\Delta C_{\mathrm{B}^{2-}, \mathrm{s}} V_{\mathrm{s}}=\Delta C_{\mathrm{B}, \mathrm{m}} V_{\mathrm{m}}$

where $\Delta C_{\mathrm{B}, \mathrm{m}}$ is the increase of the eluent concentration in the mobile phase and $V_{\mathrm{s}}$ and $V_{\mathrm{m}}$ are the volumes of the stationary and mobile phases in the column, respectively. The eluent ions in the mobile phase are not retarded by the resin in the $\mathrm{B}^{2-}$ form and the eluent peak is eluted after $V_{\mathrm{m}} \mathrm{ml}$ of eluent has been added (Fig. 1c). Transport of the sample ions through the column is accompanied by the transport of the local deficiency of eluent ions in the stationary phase (Fig. 1c). When the sample ions $\mathrm{X}^{-}$are eluted 


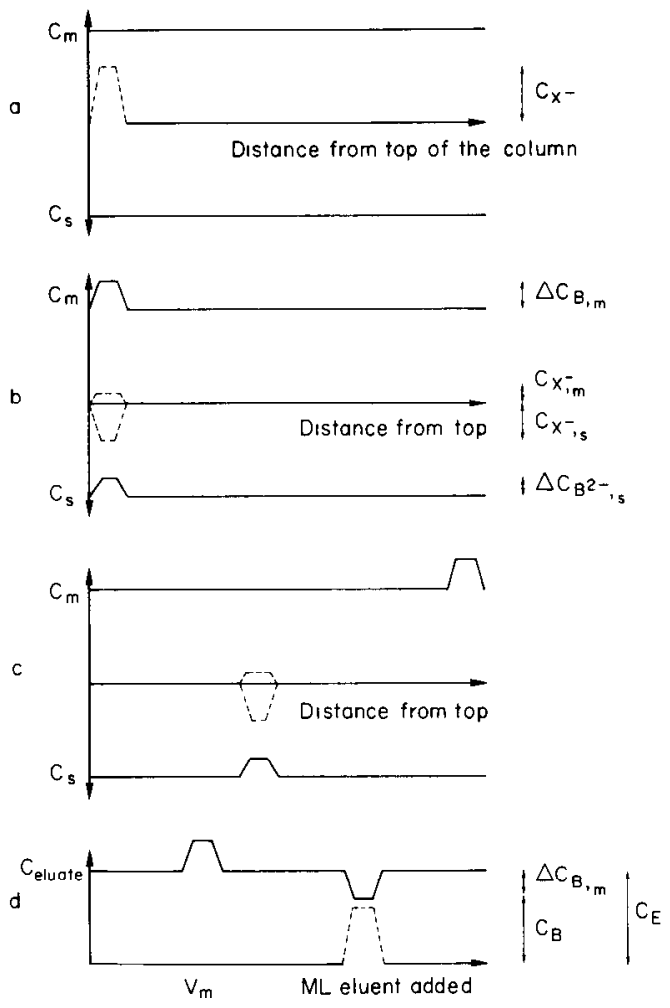

Fig. 1. Displacement of eluent ions from the separator column by sample ions: (-) eluent; (--) sample. (a) Situation in the column after injection of the sample and before equilibration; (b) after equilibration; (c) after the addition of $V_{m} \mathrm{ml}$ of eluent; (d) situation in the eluent after elution of the sample.

from the separator column, the concentration of $\mathrm{X}^{-}$in the eluate $\left(C_{\mathrm{X}^{-}}\right)$can be calculated as follows. For the last section of the column, containing a volume $\mathrm{d} V_{\mathrm{m}}$ of mobile phase and a volume $\mathrm{d} V_{\mathrm{s}}$ of stationary phase, and $\mathrm{d} n_{\mathrm{X}^{-}, \mathrm{m}}$ moles of sample ions in the mobile phase and $\mathrm{d} n_{\mathrm{X}^{-}, \mathrm{s}}$ moles of sample ions in the stationary phase, it holds that

$\mathrm{d} n_{\mathrm{X}^{-}, \mathrm{m}}+\mathrm{d} n_{\mathrm{X}^{-}, \mathrm{s}}=c_{\mathrm{X}^{-}, \mathrm{m}} \mathrm{d} V_{\mathrm{m}}+c_{\mathrm{X}^{-}, \mathrm{s}} \mathrm{d} V_{\mathrm{s}}$

Division by $\mathrm{d} V_{\mathrm{m}}$ gives

$\mathrm{d} n_{\mathrm{X}^{-}, \text {tot }} / \mathrm{d} V_{\mathrm{m}}=c_{\mathrm{X}^{-}, \mathrm{m}}+c_{\mathrm{X}^{-}, \mathrm{s}} V_{\mathrm{s}} / V_{\mathrm{m}}$

If the increase in peak width that occurs during elution of the sample peak is neglected, then when a volume $d V_{m}$ of eluent flows into (and out of) the column, $\mathrm{d} n_{\mathrm{X}^{-}}$, tot moles of ions leave the last section and enter the eluate (while $\mathrm{d} n_{\mathrm{X}^{-}, \text {tot }}^{\prime}$ moles of ions enter the last section from the preceding section). The concentration of the sample ions in the eluate $c_{\mathrm{X}^{-}}$is equal to $\mathrm{d} n_{\mathrm{X}^{-}}$, tot $\mathrm{d} V_{\mathrm{m}}$, so that $c_{\mathrm{X}^{-}}=c_{\mathrm{X}^{-}, \mathrm{m}}+c_{\mathrm{X}^{-}, \mathrm{s}} V_{\mathrm{s}} / V_{\mathrm{m}}$. The capacity factor $k^{\prime}$ is defined as 
$k^{\prime}=c_{\mathrm{X}^{-}, \mathrm{s}} V_{\mathrm{s}} / c_{\mathrm{X}^{-}, \mathrm{m}} V_{\mathrm{m}}$. Combination of the expressions for $c_{\mathrm{X}^{-}}$and $k^{\prime}$ yields

$c_{\mathrm{X}^{-}, \mathrm{s}}=\left[k^{\prime} /\left(k^{\prime}+1\right)\right] c_{\mathrm{X}^{-}} V_{\mathrm{m}} / V_{\mathrm{s}}$

Then $\Delta c_{\mathrm{B}^{2-}, \mathrm{m}}$ can be calculated as a function of $c_{\mathrm{X}^{-}}$, by using Eqns. 1, 2 and 5: $\Delta c_{\mathrm{B}_{\mathrm{m}} \mathrm{m}}=0.5\left[k^{\prime} /\left(k^{\prime}+1\right)\right] c_{\mathrm{X}^{-}}=\gamma c_{\mathrm{X}^{-}}$, with $\gamma=0.5\left[k^{\prime} /\left(k^{\prime}+1\right)\right]$. When $c_{\mathrm{B}}$ is the actual eluent concentration in the eluate, (where $c_{\mathrm{B}}=c_{\mathrm{B}^{2-}}+c_{\mathrm{HB}^{-}}+$ $c_{\mathrm{H}_{2} \mathrm{~B}}$ ), the sum of $c_{\mathrm{B}}$ and $\Delta c_{\mathrm{B}, \mathrm{m}}$ is equal to the original eluent concentration $c_{\mathrm{E}}$ (Fig. 1d):

$c_{\mathrm{E}}=c_{\mathrm{B}}+\Delta c_{\mathrm{B}, \mathrm{m}}=c_{\mathrm{B}}+\gamma c_{\mathrm{X}^{-}}$

It should be realized that Eqn. 6 is valid not only in the absence but also in the presence of sample ions $\mathrm{X}^{-}$.

In the situation considered, a sample anion $\mathrm{X}^{-}$is eluted with $\mathrm{B}^{2-}$ and, in the eluate of the suppressor column, the sample anion is present as a strong acid $\mathrm{HX}$ and the eluent is present as a weak acid $\mathrm{H}_{2} \mathrm{~B}$. The equilibrium for the weak acid is $\mathrm{H}_{2} \mathrm{~B} \rightleftharpoons \mathrm{H}^{+}+\mathrm{HB}^{-}$, with the equilibrium constant $K_{\mathrm{a} 1}=$ $c_{\mathrm{H}^{+}} c_{\mathrm{HB}^{-}} / c_{\mathrm{H}_{2} \mathrm{~B}}$. The second ionization step is neglected (see below). After eluent suppression, the total eluent concentration $c_{\mathrm{E}}$ can be written (see Eqn. 6) as $c_{\mathrm{E}}=c_{\mathrm{HB}^{-}}+c_{\mathrm{H}_{2} \mathrm{~B}}+\gamma c_{\mathrm{X}^{-}}$. Further, because of electroneutrality, $c_{\mathrm{H}^{+}}=c_{\mathrm{X}^{-}}+c_{\mathrm{HB}^{-}}$. In the eluate of the suppressor column, $c_{\mathrm{OH}^{-}}$is negligibly small (see below). Thus, from these expressions for $K_{\mathrm{a} 1}, c_{\mathrm{E}}$ and $c_{\mathrm{H}^{+}}$,

$c_{\mathrm{H}^{+}}=0.5\left\{c_{\mathrm{X}^{-}}-K_{\mathrm{a} 1}+\left[\left(c_{\mathrm{X}^{-}}+K_{\mathrm{a} 1}\right)^{2}+4 K_{\mathrm{a} 1}\left(\dot{c}_{\mathrm{E}}-\gamma c_{\mathrm{X}^{-}}\right)\right]^{1 / 2}\right\}$

$c_{\mathrm{HB}^{-}}=0.5\left\{-c_{\mathrm{X}^{-}}-K_{\mathrm{al}}+\left[\left(c_{\mathrm{X}^{-}}+K_{\mathrm{a} 1}\right)^{2}+4 K_{\mathrm{a} 1}\left(c_{\mathrm{E}}-\gamma c_{\mathrm{X}^{-}}\right)\right]^{1 / 2}\right\}$

The conductivity detector measures the sum of the conductivities of all the ions in the eluate. When $c_{i}$ is the concentration of ion $i$ in the eluate, $\Lambda_{i}$ is its equivalent conductance and $S_{T}$ is the measured total conductivity, including the contribution of the eluent, $S_{\mathrm{T}}$ is given by

$\sum_{i} c_{i} \Lambda_{i}=c_{\mathrm{X}^{-}} \Lambda_{\mathrm{X}^{-}}+c_{\mathrm{H}^{+}} \Lambda_{\mathrm{H}^{+}}+c_{\mathrm{HB}^{-}} \Lambda_{\mathrm{HB}^{-}}=P S_{\mathrm{T}}$

where $P$ is the cell constant of the conductivity cell. If $S_{\mathrm{E}}$ is the eluent conductivity (with zero sample concentration), then $P S_{\mathrm{E}}=c_{\mathrm{H}^{+}} \Lambda_{\mathrm{H}^{+}}+c_{\mathrm{HB}^{-}} \Lambda_{\mathrm{HB}^{-}}$, which can be rewritten, using the expressions for $K_{\mathrm{a} 1}$ and $c_{\mathrm{E}}$, as

$P S_{\mathrm{E}}=0.5\left(\Lambda_{\mathrm{H}^{+}}+\Lambda_{\mathrm{HB}^{-}}\right)\left[-K_{\mathrm{a} 1}+\left(K_{\mathrm{a} 1}^{2}+4 c_{\mathrm{E}} K_{\mathrm{a} 1}\right)^{1 / 2}\right]$

If $S_{\mathrm{N}}$ is the conductivity, compensated for the background eluent conductivity, then $S_{\mathrm{N}}=S_{\mathrm{T}}-S_{\mathrm{E}}$ and $S_{\mathrm{N}}$ is equal to

$$
\begin{aligned}
& S_{\mathrm{N}} P=c_{\mathrm{X}^{-}} \Lambda_{\mathrm{X}^{-}}+c_{\mathrm{H}^{+}} \Lambda_{\mathrm{H}^{+}}+c_{\mathrm{HB}^{-}} \Lambda_{\mathrm{HB}^{-}}-0.5\left(\Lambda_{\mathrm{H}^{+}}+\Lambda_{\mathrm{HB}^{-}}\right)\left[-K_{\mathrm{al}}\right. \\
& \left.\quad+\left(K_{\mathrm{a} 1}^{2}+4 c_{\mathrm{E}} K_{\mathrm{a} 1}\right)^{1 / 2}\right]
\end{aligned}
$$

When $c_{\mathrm{H}^{+}}$and $c_{\mathrm{HB}^{-}}$are both expressed in terms of $c_{\mathrm{X}^{-}}$(with Eqns. 7 and 8), then

$$
S_{\mathrm{N}} P=c_{\mathrm{X}^{-}} \Lambda_{\mathrm{X}^{-}}+0.5 \Lambda_{\mathrm{H}^{+}}\left\{c_{\mathrm{X}^{-}}-K_{\mathrm{a} 1}+\left[\left(c_{\mathrm{X}^{-}}+K_{\mathrm{a} 1}\right)^{2}+4 K_{\mathrm{a} 1}\left(c_{\mathrm{E}}-\gamma c_{\mathrm{X}^{-}}\right)\right]^{1 / 2}\right\}
$$




$$
\begin{aligned}
& +0.5 \Lambda_{\mathrm{HB}^{-}}\left\{-c_{\mathrm{X}^{-}}-K_{\mathrm{a} 1}+\left[\left(c_{\mathrm{X}^{-}}+K_{\mathrm{a} 1}\right)^{2}+4 K_{\mathrm{a} 1}\left(\dot{c}_{\mathrm{E}}-\gamma c_{\mathrm{X}^{-}}\right)\right]^{1 / 2}\right\} \\
& -0.5\left(\Lambda_{\mathrm{H}^{+}}+\Lambda_{\mathrm{HB}^{-}}\right)\left[-K_{\mathrm{a} 1}+\left(K_{\mathrm{a} 1}^{2}+4 c_{\mathrm{E}} K_{\mathrm{a} 1}\right)^{1 / 2}\right]
\end{aligned}
$$

Equation 12 can be rearranged to a quadratic equation in the unknown concentration $c_{\mathrm{X}^{-}}$

$$
\mathrm{A} c_{\mathrm{X}^{-}}^{2}+\mathrm{B} c_{\mathrm{X}^{-}}+\mathrm{C}=0
$$

where $\mathrm{A}=\left(\Lambda_{\mathrm{H}^{+}}+\Lambda_{\mathrm{X}^{-}}\right)\left(\Lambda_{\mathrm{X}^{-}}-\Lambda_{\mathrm{HB}^{-}}\right)$

$\mathrm{B}=-0.5\left(2 \Lambda_{\mathrm{X}^{-}}+\Lambda_{\mathrm{H}^{+}}-\Lambda_{\mathrm{HB}^{-}}\right)\left(\Lambda_{\mathrm{H}^{+}}+\Lambda_{\mathrm{HB}^{-}}\right)\left(K_{\mathrm{a} 1}^{2}+4 c_{\mathrm{E}} K_{\mathrm{a} 1}\right)^{1 / 2}$

$$
-S_{\mathrm{N}} P\left(2 \Lambda_{\mathrm{X}^{-}}+\Lambda_{\mathrm{H}^{+}}-\Lambda_{\mathrm{HB}^{-}}\right)-0.5 K_{\mathrm{al}}\left(\Lambda_{\mathrm{H}^{+}}+\Lambda_{\mathrm{HB}^{-}}\right)^{2}(1-2 \gamma)
$$

$\mathrm{C}=\left(S_{\mathrm{N}} P\right)^{2}+S_{\mathrm{N}} P\left(\Lambda_{\mathrm{H}^{+}}+\Lambda_{\mathrm{HB}^{-}}\right)\left(K_{\mathrm{a} 1}^{2}+4 c_{\mathrm{E}} K_{\mathrm{a} 1}\right)^{1 / 2}$

$c_{\mathrm{X}^{-}}$is calculated with the square root formula:

$c_{\mathrm{X}^{-}}=-\mathrm{B}+\left(\mathrm{B}^{2}-4 \mathrm{AC}\right)^{1 / 2} / 2 \mathrm{~A}$

This means that $c_{\mathrm{X}^{-}}$can be calculated from the measured conductivity $S_{\mathrm{N}}$ with Eqns. 14-17. The physical constants $\Lambda_{\mathrm{H}^{+}}, \Lambda_{\mathrm{HB}^{-}}, \Lambda_{\mathrm{X}^{-}}$and $K_{\mathrm{a} 1}$, the eluent concentration $c_{\mathrm{E}}$, the cell constant $P$ and the value of $\gamma$ (or the capacity factor $k^{\prime}$ ) must be known. The capacity factor is calculated from chromatographic retention data and $P$ is determined by calibrating the conductivity cell with $\mathrm{KCl}$ solutions of known concentrations.

The effect of the suppression of the ionization of the weak acid is illustrated for two weak acids, succinic acid and carbonic acid. These acids originate after suppression of succinate and carbonate eluent, respectively. Figure 2 shows the effects of increasing chloride concentration $\left(c_{\mathrm{Cl}_{1}}\right)$ in the suppressor eluate on the $\mathrm{H}^{+}$concentration $\left(c_{\mathrm{H}^{+}}\right)$and on the concentrations of the monobasic eluent ions hydrogensuccinate $\left(c_{\mathrm{HSu}^{-}}\right)$and hydrogen carbonate $\left(c_{\mathrm{HCO}_{3}^{-}}\right)$, respectively. The value of $c_{\mathrm{H}^{+}}$is calculated with Eqn. 7; $c_{\mathrm{HSu}^{-}}$and $c_{\mathrm{HCO}_{3}^{-}}$are calculated from Eqn. 8 with $c_{\mathrm{E}}=1.4 \times 10^{-3} \mathrm{~mol}^{-1}$ and $c_{\mathrm{E}}=3 \times 10^{-3} \mathrm{~mol} \mathrm{l}^{-1}$, respectively (eluent concentrations commonly used in ion chromatography). The $\mathrm{p} K_{\mathrm{a} 1}$ values applied were 4.16 for succinic acid and 6.37 for carbonic acid. Capacity factors for chloride were 1.26 in $1.4 \times$ $10^{-3} \mathrm{~mol} \mathrm{l}^{-1}$ sodium succinate and 1.52 in $3 \times 10^{-3} \mathrm{~mol} \mathrm{l}^{-1}$ sodium carbonate.

Some results are as follows. First, as carbonic acid is a much weaker acid than succinic acid, both $c_{\mathrm{HB}^{-}}$and $c_{\mathrm{H}^{+}}$are smaller in carbonic acid. Second, the $\mathrm{pH}$ in the succinic acid eluate is 3.56 or lower and in the carbonic acid eluate 4.45 or lower. It is clear that $c_{\mathrm{OH}^{-}}$is extremely small and can be neglected in the equation $c_{\mathrm{H}^{+}}=c_{\mathrm{X}^{-}}+c_{\mathrm{HB}^{-}}$. Third, the $\mathrm{p} K_{\mathrm{a} 2}$ values for succinic and carbonic acids are 5.61 and 10.25 , respectively, and the $\mathrm{pH}$ of the two eluates is $\leqslant 3.56$ and $\leqslant 4.45$, respectively, which means that the ratio $c_{\mathrm{B}^{2}} / c_{\mathrm{HB}^{-}}$for both eluates is less than $1 \%$. For this reason, the second ionization step, $\mathrm{HB}^{-} \rightleftharpoons \mathrm{H}^{+}+\mathrm{B}^{2-}$, of the weak acid $\mathrm{H}_{2} \mathrm{~B}$ is not considered in the equation $c_{\mathrm{E}}=c_{\mathrm{HB}^{-}}+c_{\mathrm{H}_{2} \mathrm{~B}}+\gamma c_{\mathrm{X}^{-}}$.

In Fig. 3 , the total ionic conductivities $\Sigma_{i} c_{i} \Lambda_{i}$ in succinic and carbonic 

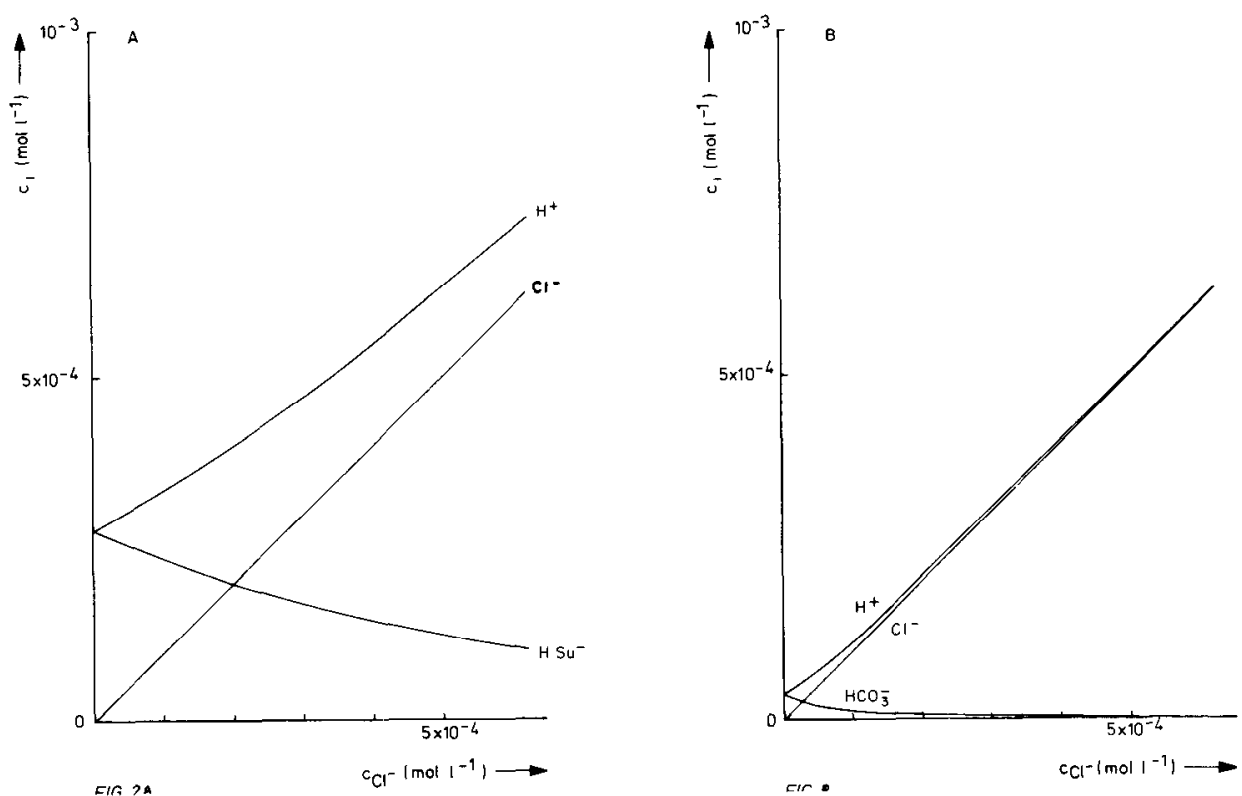

Fig. 2. Dissociation of (A) $1.4 \times 10^{-3} \mathrm{~mol} \mathrm{l}^{-1}$ succinic acid and (B) $3 \times 10^{-3} \mathrm{~mol} \mathrm{l}^{-1}$ carbonic acid as a function of chloride concentration.

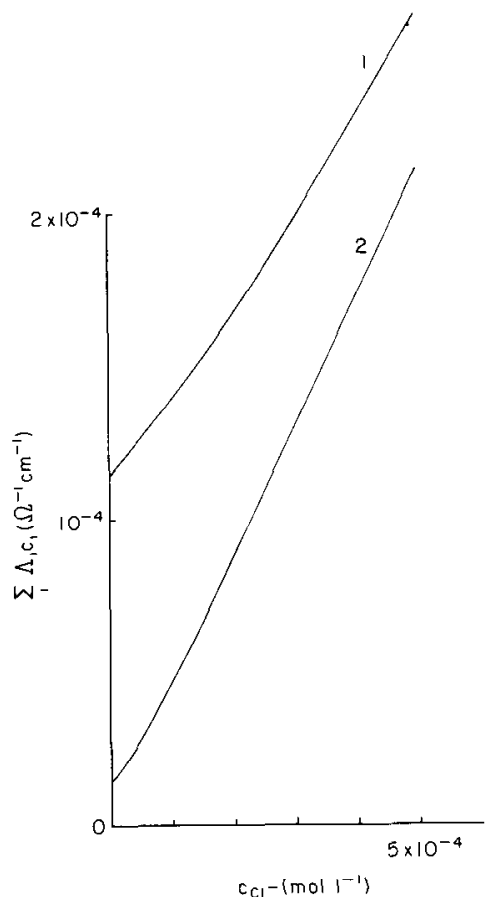

Fig. 3. Total ionic conductivity in $1.4 \times 10^{-3} \mathrm{~mol} \mathrm{l}^{-1}$ succinic acid (curve 1) and $3 \times 10^{-3}$ mol $1^{-1}$ carbonic acid (curve 2) as a function of chloride concentration. 
acids are calculated as a function of $c_{\mathrm{Cl}^{-}}$, using Eqn. 9. The $\Lambda_{i}$ values applied were $76.3 \Omega^{-1} \mathrm{~cm}^{2} \mathrm{eq}^{-1}$ for chloride, 350 for $\mathrm{H}^{+}, 60$ for hydrogensuccinate and 44.5 for hydrogencarbonate ions [5]. As can be seen, both plots are curved.

\section{EXPERIMENTAL}

\section{Chemicals}

Zipax SAX, a pellicular anion exchanger with a particle diameter of 25$37 \mu \mathrm{m}$ and a capacity of about $12 \mu \mathrm{eq} \mathrm{g}^{-1}$ dry material (DuPont de Nemours) was used in the separation column. The cation exchanger AG 50W-X16 (BioRad), with a capacity of about $5 \mathrm{meq}^{-1}$ dry resin was used in the suppressor columns. Sodium succinate ("Baker grade") and sodium carbonate (99.6\%) were obtained from Baker Chemicals.

\section{Column packing and measuring procedure}

The ion chromatograph and column packing apparatus are described in detail elsewhere [4] . A $200 \times 4.5 \mathrm{~mm}$ column was packed with Zipax SAX beads and two $150 \times 2.0 \mathrm{~mm}$ suppressor columns were packed with AG $50 \mathrm{~W}-\mathrm{X} 16$ using the slurry technique [4]. A $100 \times 4.0 \mathrm{~mm}$ glass column was packed by pumping over Dionex anion-exchange material from a 250 $\times 4.5 \mathrm{~mm}$ prepacked Dionex column. The separation column, suppressor column and detector cell were thermostated at $25.0^{\circ} \mathrm{C}$.

Eluents were prepared by dissolving $1.0599 \mathrm{~g}$ of sodium carbonate and $2.7015 \mathrm{~g}$ of sodium succinate hexahydrate, respectively, in $1 \mathrm{l}$ of deionized water. These solutions were then diluted to $3 \times 10^{-3} \mathrm{~mol} \mathrm{l}^{-1}$ sodium carbonate and $1.4 \times 10^{-3} \mathrm{~mol}^{-1}$ sodium succinate, respectively.

A FORTRAN computer program (available on request) was written to calculate the total amount of sample in the eluate from conductivity data. The program consists of the following parts. First, conductivity is measured at regular time intervals. This time interval is increased after each peak, because the peak width increases with the retention time. Second, a peak search routine indicates the start, maximum and end of each peak. The baseline is determined before and after the peak and the mean value of the baseline is subtracted from each point on the chromatogram. Third, the sample concentration in each point is calculated with Eqn. 17. Finally, the total amount of sample is obtained by integrating the calculated sample concentrations over the total eluted peak volume.

\section{RESULTS AND DISCUSSION}

The cell constant $P$ was determined by measuring the conductivity $S$ of $10^{-4} \mathrm{~mol} \mathrm{l}^{-1} \mathrm{KCl}$ at $25.0^{\circ} \mathrm{C}$. The response of the conductivity cell was linear up to $5 \times 10^{-4} \mathrm{~mol} \mathrm{l}^{-1} \mathrm{KCl}$ according to the relation $S \times P=10^{3} c\left(\Lambda_{\mathrm{K}^{+}}+\right.$ $\left.\Lambda_{\mathrm{Cl}^{-}}\right)$wherein $\Lambda_{\mathrm{K}^{+}}$and $\Lambda_{\mathrm{Cl}^{-}}$are 73.5 and $76.3 \Omega^{-1} \mathrm{eq}^{-1} \mathrm{~cm}^{2}$, respectively, $c$ is 
the $\mathrm{KCl}$ concentration ( $\mathrm{mol} \mathrm{l}^{-1}$ ) and $S$ is the conductivity ( $\left.\mu \mathrm{mho}\right) . P$ was found to be $1.69 \mathrm{~cm}^{-1}$.

Capacity factor data for chloride, nitrate and sulphate were calculated with the equation $k^{\prime}=\left(V_{\mathrm{R}}-V_{\mathrm{M}}\right) / V_{\mathrm{m}}$, wherein $V_{\mathrm{R}}$ and $V_{\mathrm{M}}$ are the retention volumes of the retarded component and water, respectively, in the separator-suppressor column combination. The $k^{\prime}$ values, listed in Table 1, were determined by injecting $2 \mu \mathrm{g}$ of each sample ion.

Calibration graphs for chloride, nitrate and sulphate were prepared for both a $200 \times 4.5 \mathrm{~mm}$ Zipax SAX column and a $100 \times 4.0 \mathrm{~mm}$ Dionex column. The eluents were $1.4 \times 10^{-3} \mathrm{~mol} \mathrm{1^{-1 }}$ sodium succinate and $3 \times 10^{-3} \mathrm{~mol} \mathrm{l}^{-1}$ sodium carbonate, respectively. A $150 \times 2.0 \mathrm{~mm} \mathrm{AG}$ $50 \mathrm{~W}-\mathrm{X} 16$ suppressor column was used in both cases. Samples with concentrations ranging from 1 to $40 \mathrm{mg} \mathrm{l}^{-1}$ were injected with a $200-\mu \mathrm{l}$ or $500-\mu \mathrm{l}$ loop.

In Table 2, experimental plate heights are listed for chloride, as well as the ratios $S_{\mathrm{p}} / c_{0}$ and $c_{\mathrm{p}} / c_{0}$, where $c_{0}$ is the known chloride concentration in the sample, $S_{\mathrm{p}}$ is the conductivity at the peak maximum, and $c_{\mathrm{p}}$ is the calculated chloride concentration at the peak maximum. It appears that on the Zipax column, $S_{\mathrm{p}} / c_{0}$ increases with $c_{0}$ for $c_{0}=1$ to $10 \mathrm{mg} \mathrm{l}^{-1}$ and decreases for $c_{0}>10 \mathrm{mg} \mathrm{l}^{-1}$. Obviously the Zipax column is overloaded if more than $10 \mathrm{mg} \mathrm{l}^{-1}$ is injected and as a result the eluted peak is broadened. This is

\section{TABLE 1}

Capacity factors $\left(k^{\prime}\right)$ for chloride, nitrate and sulphate on a Zipax SAX column and a Dionex column

Eluents: $1.4 \times 10^{-3} \mathrm{~mol} \mathrm{l}^{-1}$ sodium succinate and $3 \times 10^{-3} \mathrm{~mol} \mathrm{l}^{-1} \mathrm{Na}_{2} \mathrm{CO}_{3}$, respectively)

\begin{tabular}{lllc}
\hline Ion & $\mathrm{Cl}^{-}$ & $\mathrm{NO}_{3}^{-}$ & $\mathrm{SO}_{4}^{2-}$ \\
$k^{\prime}$ (Zipax) & 1.26 & 5.46 & 8.38 \\
$k^{\prime}$ (Dionex) & 1.52 & 6.23 & 13.21 \\
\hline
\end{tabular}

TABLE 2

Calibration for chloride on a Zipax SAX column and a Dionex column, based on conductivity data at the peak maximum ${ }^{a}$

\begin{tabular}{|c|c|c|c|c|c|c|}
\hline \multirow[t]{2}{*}{$c_{0}$} & \multicolumn{3}{|c|}{ Zipax SAX } & \multicolumn{3}{|c|}{ Dionex } \\
\hline & $H$ & $S_{\mathrm{p}} / c_{0}$ & $10^{5} c_{\mathrm{p}} / c_{\mathrm{o}}$ & $H$ & $S_{\mathrm{p}} / c_{0}$ & $10^{5} c_{\mathrm{p}} / c_{0}$ \\
\hline 1 & 0.12 & 6.88 & 2.37 & 0.18 & 8.70 & 2.66 \\
\hline 2 & 0.13 & 7.03 & 2.38 & 0.18 & 9.55 & 2.63 \\
\hline 5 & 0.13 & 7.18 & 2.33 & 0.18 & 11.01 & 2.58 \\
\hline 10 & 0.13 & 7.21 & 2.20 & 0.19 & 11.82 & 2.53 \\
\hline 20 & 0.17 & 6.77 & 1.91 & 0.21 & 12.19 & 2.47 \\
\hline 40 & 0.25 & 5.73 & 1.49 & 0.25 & 11.63 & 2.29 \\
\hline
\end{tabular}

${ }^{a} c_{0}$ : concentration of chloride injected $\left(\mathrm{mg} \mathrm{l}^{-1}\right) . H$ : plate height $(\mathrm{mm}) . S_{\mathrm{p}}$ : peak height $(\mu \mathrm{mho}), c_{\mathrm{p}}$ : peak height $\left(\mathrm{mol} \mathrm{l}^{-1}\right)$. Injected sample volume: $200 \mu 1$. 
affirmed by the measured plate heights: $H$ is constant $(0.13 \mathrm{~mm})$ for $c_{0}=$ 1 to $10 \mathrm{mg} \mathrm{l}^{-1}$ but increases for $c_{0}>10 \mathrm{mg} \mathrm{l}^{-1}$. Consequently, $c_{\mathrm{p}} / c_{0}$ is constant only for $c_{0}=1$ to $5 \mathrm{mg} \mathrm{l}^{-1}$ and decreases when $c_{0}>5 \mathrm{mg} \mathrm{l}^{-1}$. The same reasoning applies for the Dionex column. It is concluded that, because of peak broadening, a calibration based on calculated sample concentrations at the peak maximum is not linear over the range $1-40 \mathrm{mg} \mathrm{l}^{-1}$.

The effect of peak broadening on the calibration is eliminated if the total amount of constituent under the peak is determined. Total amounts of chloride, nitrate and sulphate were so determined from conductivity measurements and the results are listed in Table $3\left(n_{1}\right.$ data). For convenience, the amounts of sample injected $\left(n_{0}\right)$ and the $n_{1} / n_{0}$ ratios are also given, as well as the conductivities at the peak maximum $S_{\mathrm{p}}$ and the $S_{\mathrm{p}} / c_{0}$ ratios. The results in Table 3 indicate again that calibration graphs based on peak heights are curved. It can be seen that the $n_{1} / n_{0}$ ratios are all about 1.0. Thus the amount of sample that is injected can be accurately determined by conductivity. In principle, no standards are required once the cell constant has been measured, but this kind of absolute calibration can be applied successfully only if the eluent flow rate, the loop volume and the capacity factors are all accurately known and if the temperature remains constant. In practice, the capacity factors vary somewhat whenever a fresh eluent or a fresh suppressor column is used. Therefore a relative calibration with two standards is advisable.

The linear regression technique was used to test the calibration graphs. Inspection of the $n_{1} / n_{0}$ values in Table 3 shows that 6 out of the 12 data at the lowest concentration are rather low. Therefore, the results obtained at $c_{0}=1 \mathrm{mg} \mathrm{l}^{-1}$ were not considered for the regression. The $n_{1}$ values obtained at the other values of $c_{0}$ are probably beset with a constant relative error. (The main contribution to the error of $n_{1}$ stems from the error of the conductivity measurements; generally, the relative error of conductivity measurements is constant.) The error in $n_{0}$ is negligible, and the values of $n_{1} / n_{0}$ are about constant. Therefore, if the relative error of $n_{1}$ is constant, the absolute error of $n_{1} / n_{0}$ is constant. Accordingly, the regression equation used was $n_{1} / n_{0}=a+b c_{0}$. The results are shown in Table 4 . It appears that the intercepts $a$ are just significant statistically, so that a single-point calibration is not warranted. Two-point calibration gives values of $s_{n_{1} / n_{0}}$ of about 0.02 , i.e., an accuracy of $2 \%$. Thus a linear calibration graph with a standard deviation of $2 \%$ can be obtained when the proposed formula is applied.

\section{Conclusions}

In ion chromatography with eluent suppression, non-linear relations between sample concentrations and conductivity values are found if the usual procedures are applied. Linear relations are found if three modifications are applied: consideration of the suppression of the eluent dissociation by the sample ions, consideration of the displacement of eluent ions in the separator column by the sample ions, and integration of the calculated 
TABLE 3

Calibration of chloride, nitrate and sulphate on Zipax SAX and Dionex columns, based on integration of conductivity data over the peak volume ${ }^{a}$

\begin{tabular}{lllllll}
\hline $\begin{array}{l}\text { Ion } \\
\text { injected }\end{array}$ & $\begin{array}{l}c_{0} \\
\left(\mathrm{mg} \mathrm{l} \mathrm{l}^{-1}\right)\end{array}$ & $\begin{array}{l}n_{0} \\
(\mu \mathrm{g})\end{array}$ & $\begin{array}{l}S_{\mathrm{p}} \\
(\mu \mathrm{mho})\end{array}$ & $\begin{array}{l}S_{\mathrm{p}} / c_{0} \\
\left(\mu \mathrm{mho} \mathrm{mg}^{-1} \mathrm{l}\right)\end{array}$ & $\begin{array}{l}n_{\mathrm{g}} \\
(\mu \mathrm{g})\end{array}$ & $n_{1} / n_{0}$ \\
\hline
\end{tabular}

(a) Zipax SAX $\left(1.4 \times 10^{-3} \mathrm{moll}^{-1}\right.$ sodium succinate eluent at $1.86 \mathrm{ml} \mathrm{min}^{-1} ; 200 \mu \mathrm{l}$ injected $)$

$\begin{array}{lrrrrll}\text { Chloride } & 1 & 0.2 & 6.88 & 6.88 & 0.194 & 0.97 \\ & 2 & 0.4 & 14.07 & 7.03 & 0.398 & 0.99 \\ & 5 & 1.0 & 35.90 & 7.18 & 0.990 & 0.99 \\ & 10 & 2.0 & 72.05 & 7.21 & 1.983 & 0.99 \\ \text { Nitrate } & 20 & 4.0 & 135.4 & 6.77 & 4.00 & 1.00 \\ & 40 & 8.0 & 229.0 & 5.73 & 8.02 & 1.00 \\ & 1 & 0.2 & 1.03 & 1.03 & 0.188 & 0.94 \\ & 2 & 0.4 & 2.08 & 1.04 & 0.390 & 0.98 \\ \text { Sulphate } & 5 & 1.0 & 5.20 & 1.04 & 0.981 & 0.98 \\ & 10 & 2.0 & 10.27 & 1.03 & 1.989 & 0.99 \\ & 20 & 4.0 & 19.83 & 0.99 & 4.05 & 1.01 \\ & 40 & 8.0 & 37.40 & 0.94 & 8.10 & 1.01 \\ & 1 & 0.2 & 0.96 & 0.96 & 0.209 & 1.05 \\ & 2 & 0.4 & 1.93 & 0.97 & 0.425 & 1.06 \\ & 5 & 1.0 & 4.85 & 0.97 & 1.045 & 1.05 \\ & 10 & 2.0 & 9.84 & 0.98 & 2.07 & 1.04 \\ & 20 & 4.0 & 20.06 & 1.00 & 4.16 & 1.04 \\ & 40 & 8.0 & 40.54 & 1.01 & 8.29 & 1.04\end{array}$

(b) Zipax $S A X\left(1.4 \times 10^{-3} \mathrm{moll}^{-1}\right.$ sodium succinate as eluent at $1.85 \mathrm{ml} \mathrm{min}^{-1} ; 500 \mu \mathrm{l}$ injected)

$\begin{array}{lrrrrrr}\text { Chloride } & 1 & 0.5 & 16.50 & 16.50 & 0.490 & 0.98 \\ & 2 & 1.0 & 33.39 & 16.70 & 0.983 & 0.98 \\ & 5 & 2.5 & 81.26 & 16.25 & 2.464 & 0.99 \\ \text { Nitrate } & 10 & 5.0 & 148.6 & 14.86 & 4.92 & 0.98 \\ & 20 & 10.0 & 250.7 & 12.54 & 9.90 & 0.99 \\ & 40 & 20.0 & 379.3 & 9.48 & 19.81 & 0.99 \\ & 1 & 0.5 & 2.55 & 2.55 & 0.477 & 0.96 \\ & 2 & 1.0 & 5.11 & 2.56 & 0.985 & 0.99 \\ \text { Sulphate } & 10 & 2.5 & 12.45 & 2.49 & 2.459 & 0.98 \\ & 20 & 5.0 & 23.77 & 2.38 & 4.96 & 0.99 \\ & 40 & 10.0 & 44.73 & 2.24 & 9.98 & 1.00 \\ & 1 & 20.0 & 84.17 & 2.10 & 19.93 & 1.00 \\ & 2 & 0.5 & 2.42 & 2.42 & 0.512 & 1.02 \\ & 5 & 1.0 & 4.87 & 2.44 & 1.031 & 1.03 \\ & 10 & 2.5 & 12.42 & 2.48 & 2.578 & 1.03 \\ & 20 & 5.0 & 25.29 & 2.53 & 5.15 & 1.03 \\ & 40 & 10.0 & 51.82 & 2.59 & 10.24 & 1.02 \\ & 0.0 & 104.6 & 2.62 & 20.26 & 1.01\end{array}$


TABLE 3 (continued)

\begin{tabular}{lllllll}
\hline $\begin{array}{l}\text { Ion } \\
\text { injected }\end{array}$ & $\begin{array}{l}c_{0} \\
\left(\mathrm{mg} \mathrm{l}^{-1}\right)\end{array}$ & $\begin{array}{l}n_{0} \\
(\mu \mathrm{g})\end{array}$ & $\begin{array}{l}S_{\mathrm{p}} \\
(\mu \mathrm{mho})\end{array}$ & $\begin{array}{l}S_{\mathrm{p}} / c_{0} \\
\left(\mu \mathrm{mho} \mathrm{mg}^{-1} \mathrm{l}\right)\end{array}$ & $\begin{array}{l}n_{1} \\
(\mu \mathrm{g})\end{array}$ & $n_{1} / n_{0}$ \\
\hline
\end{tabular}

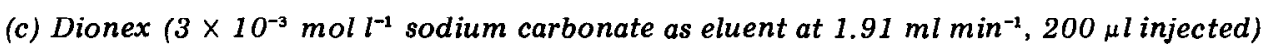

$\begin{array}{lrrrrll}\text { Chloride } & 1 & 0.2 & 8.70 & 8.70 & 0.206 & 1.03 \\ & 2 & 0.4 & 19.09 & 9.55 & 0.414 & 1.03 \\ & 5 & 1.0 & 55.05 & 11.01 & 1.022 & 1.02 \\ & 10 & 2.0 & 118.2 & 11.82 & 2.05 & 1.02 \\ \text { Nitrate } & 20 & 4.0 & 243.7 & 12.19 & 4.09 & 1.02 \\ & 40 & 8.0 & 465.3 & 11.63 & 8.09 & 1.01 \\ & 1 & 0.2 & 1.14 & 1.14 & 0.194 & 0.97 \\ & 2 & 0.4 & 2.30 & 1.15 & 0.400 & 1.00 \\ \text { Sulphate } & 5 & 1.0 & 5.76 & 1.15 & 1.013 & 1.01 \\ & 10 & 2.0 & 11.66 & 1.17 & 2.04 & 1.02 \\ & 20 & 4.0 & 23.98 & 1.20 & 4.10 & 1.02 \\ & 40 & 8.0 & 50.37 & 1.26 & 8.16 & 1.02 \\ & 1 & 0.2 & 0.84 & 0.84 & 0.200 & 1.00 \\ & 2 & 0.4 & 1.71 & 0.86 & 0.414 & 1.04 \\ & 10 & 1.0 & 4.45 & 0.89 & 1.025 & 1.02 \\ & 20 & 2.0 & 9.35 & 0.94 & 2.05 & 1.03 \\ & 40 & 4.0 & 19.99 & 1.00 & 4.12 & 1.03 \\ & 10 & 8.0 & 40.56 & 1.01 & 8.17 & 1.02\end{array}$

(d) Dionex $\left(3 \times 10^{-3} \mathrm{~mol} \mathrm{l}^{-1}\right.$ sodium carbonate as eluent at $1.92 \mathrm{ml} \mathrm{min}^{-1}, 500 \mu \mathrm{l}$ injected $)$

\begin{tabular}{lrrrrrr} 
Chloride & 1 & 0.5 & 23.41 & 23.41 & 0.507 & 1.01 \\
& 2 & 1.0 & 52.13 & 26.06 & 1.015 & 1.02 \\
& 5 & 2.5 & 139.3 & 27.90 & 2.531 & 1.01 \\
Nitrate & 10 & 5.0 & 273.1 & 27.31 & 5.03 & 1.01 \\
& 20 & 10.0 & 494.4 & 24.72 & 9.98 & 1.00 \\
& 1 & 0.5 & 2.74 & 2.74 & 0.492 & 0.98 \\
& 2 & 1.0 & 5.48 & 2.74 & 1.005 & 1.01 \\
Sulphate & 5 & 2.5 & 13.81 & 2.76 & 2.513 & 1.01 \\
& 10 & 5.0 & 28.51 & 2.85 & 5.03 & 1.01 \\
& 20 & 10.0 & 60.69 & 3.03 & 9.96 & 1.00 \\
& 40 & 20.0 & 126.9 & 3.17 & 19.96 & 1.00 \\
& 1 & 0.5 & 2.11 & 2.11 & 0.503 & 1.01 \\
& 2 & 1.0 & 4.35 & 2.18 & 1.012 & 1.01 \\
& 5 & 2.5 & 11.72 & 2.34 & 2.542 & 1.02 \\
& 10 & 5.0 & 24.44 & 2.44 & 5.06 & 1.01 \\
& 20 & 10.0 & 48.87 & 2.44 & 9.97 & 1.00 \\
& 40 & 20.0 & 92.83 & 2.32 & 19.87 & 0.99 \\
\hline
\end{tabular}

${ }^{a} n_{0}$ : amount of sample injected. $n_{1}$ : amount of sample found. Further legend as in Table 2.

concentrations over the total eluted peak area. Linear calibration based on peak heights cannot be obtained as the peak width increases with the sample concentration when constant volumes are injected. With these modifications, linear calibration graphs were obtained for chloride, nitrate and sulphate ions in both succinate and carbonate eluents. 


\section{TABLE 4}

Results obtained in calibration for chloride, nitrate and sulphate on Zipax and Dionex columns

\begin{tabular}{|c|c|c|c|c|c|c|c|c|c|}
\hline \multirow{2}{*}{$\begin{array}{l}\text { Separation column/ } \\
\text { injection loop }\end{array}$} & \multicolumn{3}{|c|}{ Chloride } & \multicolumn{3}{|c|}{ Nitrate } & \multicolumn{3}{|c|}{ Sulphate } \\
\hline & $a$ & $b$ & $s_{n_{1} / n_{2}}$ & $a$ & $b$ & $s_{n_{1}} / n_{2}$ & $a$ & $b$ & $s_{n_{1} / n}$ \\
\hline Zipax $/ 200 \mu 1$ & 0.99 & 0.0003 & 0.005 & 0.98 & 0.0010 & 0.018 & 1.05 & -0.0005 & 0.011 \\
\hline Zipax $/ 500 \mu l$ & 0.98 & 0.0002 & 0.004 & 0.99 & 0.0004 & 0.007 & 1.03 & -0.0005 & 0.008 \\
\hline Dionex/200 $\mu 1$ & 1.03 & -0.0005 & 0.009 & 1.01 & 0.0004 & 0.010 & 1.03 & -0.0002 & $0.00 E$ \\
\hline Dionex/500 $\mu \mathrm{l}$ & 1.02 & -0.0010 & 0.008 & 1.01 & -0.0002 & 0.005 & 1.02 & -0.0006 & 0.010 \\
\hline
\end{tabular}

\section{REFERENCES}

1 M. Small, T. S. Stevens and W. C. Bauman, Anal. Chem., 47 (1975) 1801.

2 J. D. Mulik and E. Sawicki (Eds.), Ion Chromatographic Analysis of Environmental Pollutants, Vol. 2, Ann Arbor Science Publishers, Ann Arbor, 1979.

3 J. Slanina, F. P. Bakker, P. A. C. Jongejan, L. van Lamoen and J. J. Möls, Anal. Chim. Acta, 130 (1981) 1.

4 M. J. van Os, J. Slanina, C. L. de Ligny, W. E. Hammers and J. Agterdenbos, Anal. Chim. Acta, 144 (1982) 73.

5 W. A. Roth and K. Scheel (Eds.), Landolt-Bornstein Physikalisch-Chemische Tabellen, dritter Ergänzungsband, Springer Verlag, Berlin, 1935, p. 2060. 